\title{
Psychological Distress after a Diagnosis of Malignant Mesothelioma in a Group of Patients and Caregivers at the National Priority Contaminated Site of Casale Monferrato
}

\author{
Michela Bonafede ${ }^{1, *} \mathbb{*}$, Antonella Granieri ${ }^{2}$, Alessandra Binazzi ${ }^{1}$, Carolina Mensi ${ }^{3}{ }^{(}$, \\ Federica Grosso ${ }^{4}$, Gianluca Santoro ${ }^{5}$, Isabella Giulia Franzoi ${ }^{2}{ }^{\mathbb{D}}$, Alessandro Marinaccio ${ }^{1}[$ \\ and Fanny Guglielmucci ${ }^{2}$ (D) \\ 1 Occupational and Environmental Medicine, Epidemiology and Hygiene Department, Italian Workers' \\ Compensation Authority (INAIL), 00143 Rome, Italy; a.binazzi@inail.it (A.B.); a.marinaccio@inail.it (A.M.) \\ 2 Department of Psychology, University of Turin, 10123 Turin, Italy; antonella.granieri@unito.it (A.G.); \\ isabellagiulia.franzoi@unito.it (I.G.F.); fanny.guglielmucci@unito.it (F.G.) \\ 3 Epidemiology Unit, Fondazione IRCCS Ca' Granda, Ospedale Maggiore Policlinico Milano, 20122 Milan, \\ Italy; carolina.mensi@unimi.it \\ 4 Mesothelioma Unit, Azienda Ospedaliera SS Antonio e Biagio e Cesare Arrigo, 15121 Alessandria, Italy; \\ federica.grosso@ospedale.al.it \\ 5 Faculty of Human and Social Sciences, UKE-Kore University of Enna, 94100 Enna, Italy; glcsnt@gmail.com \\ * Correspondence: m.bonafede@inail.it; Tel.: +39-06-54872301
}

Received: 30 April 2020; Accepted: 15 June 2020; Published: 17 June 2020

\begin{abstract}
Background: Patients of malignant mesothelioma (MM) and their caregivers face significant physical and psychological challenges. The purpose of the present study is to examine the emotional impact after the diagnosis of MM in a group of patients and familial caregivers in a National Priority Contaminated Site (NPCS). Methods: A sample of 108 patients and 94 caregivers received a sociodemographic/clinical questionnaire, the Beck Depression Inventory II, the Davidson Trauma Scale, the Coping Orientation to the Problems Experienced-New Italian Version, and the Defense style questionnaire. The risk of depressive and post-traumatic stress disorder (PTSD) symptoms in relation to the strategies of coping and defense mechanisms was estimated in patients and caregivers separately by logistic regression models. Results: For patients, a high risk of depression was associated with high usage of Defense Style Questionnaire (DSQ) Isolation (OR: 53.33; 95\% CI: 3.22-882.30; $p=0.01$ ) and DSQ Somatization (OR: 16.97; 95\% CI: 1.04-275.90; $p=0.05$ ). Other significant risks emerged for some coping strategies and some defenses regarding both depression and trauma in patients and caregivers. Conclusions: This research suggests that for both patients and caregivers unconscious adaptive processes have a central role in dealing with overwhelming feelings related to the disease.
\end{abstract}

Keywords: malignant mesothelioma; emotional distress; contaminated site; depression; trauma; post-traumatic stress disorder (PTSD)

\section{Introduction}

The impact of asbestos is currently a serious concern for public health. Recently, Furuya et al. [1] summarized the latest evidence on the magnitude of asbestos-related diseases, showing a global estimate of 255,000 deaths/years $(243,223-260,029)$ due to asbestos. Moreover, work-related exposures are responsible for 233,000 deaths $(222,322-242,802)$. Along with the progressive growth of these 
occurrences, Malignant Mesothelioma (MM) death numbers are also increasing constantly, reaching a global total of 30,208 cases, $91.4 \%$ of those due to occupational exposure [1], mostly in men.

Due to the large use of asbestos before the national ban in 1992 [2], Italy is one of the countries most involved in the monitoring and control of asbestos-related diseases. Currently, Italy is suffering a severe epidemic of asbestos-related diseases. For this reason, Italy has implemented an epidemiological surveillance system of mesothelioma incidence through a national registry (ReNaM: Registro Nazionale dei Mesoteliomi) with the aim to provide evidence regarding pleural mesothelioma occurrence and the modalities of asbestos exposure involved. More than 27,000 malignant mesothelioma cases have been collected from 1993 to 2015, with exposures defined for around 70\%. Environmental and domestic exposures have been reported in $4.4 \%$ and $4.9 \%$ of cases, respectively [3].

Mesothelioma incidence has been investigated at several National Priority Contaminated Sites (NPCSs) in Italy in order to obtain estimates on the impact of asbestos on residents. Statistically significant excesses of mesothelioma incidence were recorded at 20 of these sites, including Casale Monferrato, where a large fiber cement factory (i.e., Eternit) is headquartered. The factory has had an impact on the health not only of workers employed at the plant (mostly men), but also that of their relatives (mostly wives) and other residents, with no other sources of asbestos exposure besides environmental pollution [4].

The standardized incidence ratios (SIR) of MM in Casale Monferrato are 910.7 (95\% CI: 816.5-1012.8) in men and 1338.1 (95\% CI: 1176.7-1515.4) in women [5].

The consequences of MM on mental health are particularly relevant in National Priority Contaminated Sites (NPCSs). Our previous studies in the NPCS of Casale Monferrato have remarked negative mental health outcomes in the whole residing population [6,7].

MM patients and their familial caregivers face significant physical and psychological challenges, such as a limited life expectancy, and poor and fatal prognosis [8]. The lack of effective treatments, together with the difficulty of communicating with physicians, underlies the increased incidence of intense emotional disturbance resulting from the diagnosis of MM [9]. Indeed, the literature has remarked that the diagnosis of $\mathrm{MM}$ is a shocking traumatic experience associated with depressive symptoms and feelings of hopelessness, helplessness and despair [10-14]. A depressed state is a common psychopathologic feature of MM [15-17] that worsens with disease progression [18]. Asbestos exposure has also been linked to post-traumatic symptomatology [18,19], presumably related to the awareness and fear of imminent death $[6,20,21]$.

Humans cope with adversity and negative emotions in adaptive and non-adaptive ways. Coping strategies and defense mechanisms are psychological processes that allow an individual to manage painful emotions arising from stressful and traumatic experiences. However, they differ in several fundamental aspects. Coping is a conscious and intentional process for managing specific internal and external demands that are believed to exceed the resources of a person. In contrast, defense mechanisms are mainly unconscious and unintentional, and aim to protect the ego from the intensity of disruptive internal/external conflicts and dangers [22]. Moreover, coping is related to an individual level of adaptation and is externally determined by a situation that leads to change, whereas defense mechanisms are thought to be related to personality traits and are thus stable over time, as well as being internally determined and proportional to the degree of reality or distorted perception [23].

Previous studies have shown that in order to face the traumatic emotions linked to MM diagnosis and its symptoms, MM patients commonly activate avoidant strategies which involve cognitive and behavioral efforts to minimize the real health danger of asbestos exposure $[9,15,21,24]$. Additionally, psychoanalytic in-depth investigations have highlighted the tendency of both MM patients and their caregivers to move away from conscious thoughts and emotions related to death through denial [13].

The purpose of the present study was to examine the emotional impact (depression and trauma) of a diagnosis of MM in a group of patients and familial caregivers in the NPCS of Casale Monferrato with a special focus on the coping strategies and defense mechanisms that are used by these two groups. 


\section{Materials and Methods}

\subsection{Procedures and Study Population}

The present study was part of the Assessing Psychological Variables in Mesothelioma (AVPM) Project, conducted at the Mesothelioma Unit of Casale Monferrato-Alessandria, Italy. The protocol was approved by the local Institutional Review Board of the University of Turin and the Azienda Ospedaliera SS Antonio e Biagio e Cesare Arrigo Ethical Committee (AVPM; 14/11/2014). The study was carried out in accordance with the Declaration of Helsinki. All subjects provided written informed consent and their anonymity was ensured.

The present study followed a cross-sectional design, having continuous recruitment between September 2014 and December 2018. Cases were selected from the medical database of the Mesothelioma Unit based on the following inclusion criteria: diagnosed with MM or being a primary familial caregiver of an MM patient, the ability to speak Italian, living in in the NPCS of Casale Monferrato and providing written informed consent. Exclusion criteria were as follows: diagnosis of a psychiatric illness or central nervous system disease, and having a caregiver with a disease related to asbestos exposure.

Potential participants were recruited through an invitation from medical staff (i.e., oncologists, nurses and psychologists) at the site, who introduced the study and gave the participants an information sheet. The response rate for both patients and caregivers was $80 \%$. In the recruitment phase, the two groups were unrelated and independent. Patients were recruited within 6 months of diagnosis. Researchers were not involved in patient care, but trained medical staff in recruitment and test administration, which was carried out by hospital psychologists in an individual setting. Data were anonymously and independently analyzed by researchers.

\subsection{Instruments}

\subsubsection{Sociodemographic and Clinical Data Collection}

An ad hoc questionnaire was used to collect sociodemographic and clinical variables including: gender, age, educational level, job, marital status, psychotherapy history, psychological examination, drugs use, type of MM, and localization. Asbestos exposure (environmental/occupational) determined through a ReNaM questionnaire (for patients only).

\subsubsection{Depression}

The Beck Depression Inventory, Second Edition (BDI-II) [25] is a 21-item self-report questionnaire assessing the presence and severity of depressive symptoms according to the Diagnostic and Statistical Manual of Mental Disorders, Fourth Edition (DSM-IV) criteria. Scores equal to or under 13 inform the absence of or minimal depression; scores between 14-19 and 20-28 indicate mild and moderate depression, respectively; while scores equal to or above 29 indicate severe depression.

The items refer to sadness, pessimism, a sense of failure, self-dissatisfaction, guilt, self-punishment, self-deprecation, self-accusation, suicidal ideas, crying, irritability, social withdrawal, indecisiveness, body image distortion, difficulties at work, sleep disturbance, fatigue, loss of appetite, weight loss, preoccupation, and decreased libido. All but two items have four possible responses of increasing intensity. For example, under sadness the responses range from "I do not feel sad" to "I am so sad or unhappy I can't stand it". The range of possible scores is $0-63$. The degree of a symptom was measured with a four-item Likert-type scale reflecting the presence or frequency of the symptom.

The BDI-II has been translated into several languages and adapted to different cultures, and its utility has been demonstrated in many studies [26]. The Italian version of the scale demonstrated good internal consistency and concurrent validity [27]. 


\subsubsection{Post-Traumatic Symptoms}

The Davidson Trauma Scale (DTS) [28] is a 17-item self-report questionnaire assessing the frequency and severity of each DSM-IV symptom of post-traumatic stress disorder (PTSD). In the present study we modified the original version (i.e., record "the trauma that is most disturbing to you"), asking participants to answer items already referring to the trauma of MM diagnosis.

Items were rated on five-point frequency $(0=$ "not at all" to $4=$ "every day") and severity scales $(0=$ "not at all distressing" to $4=$ "extremely distressing"). Respondents were asked to identify the trauma that is most disturbing to them and to rate, in the past week, how much trouble they have had with each symptom (sample item "Have you had painful images, memories or thoughts of the event?"). The DTS yields a frequency score (ranging from 0 to 68), severity score (ranging from 0 to 68), and total score (ranging from 0 to 136).

Items can be categorized into three clusters corresponding to the DSM-IV diagnostic criteria for PTSD diagnosis: Criteria B "re-experimentation" (RE; items 1-5); Criteria C "avoidance and numbing" (AN; items 6-12); Criteria D "hyper-activation" (HA; items 13-17). Further research has shown that DTS could be used to differentiate patients with PTSD and partial PTSD from those with no PTSD in the general population, and to detect differences between treatments of differing efficacy [29]. DTS has been used in several previous studies to detect PTSD in Italian population $[30,31]$.

\subsubsection{Coping Strategies}

The Coping Orientation to Problems Experienced-New Italian Version is a 60-item self-report questionnaire assessing the frequency of strategies usually activated to cope with stressful events on a four-point scale (1-4) [32]. Response choices are the following: "I usually do not do this at all", "I usually do this a little bit", "I usually do this a medium amount", and "I usually do this a lot". Example statements from the inventory include "I concentrate my efforts on doing something about it" and "I take additional action to try to get rid of the problem".

In the present study, we asked participants to answer the questions by considering the MM diagnosis as the stressful event. In contrast to the original version, the new Italian version has a five-factor structure (social support, avoidance strategies, positive attitudes, problem solving and turning to religion) [33]. The dimensions were large and essentially independent, with good internal consistency (alpha range 0.70-0.91; mean inter-item correlation range: $0.13-0.15$ ) and stability (test-retest range $0.68-0.93)$.

\subsubsection{Defense Mechanisms}

The Defense Style Questionnaire (DSQ-40) [34] is a 40-item self-report questionnaire widely used to assess defense mechanisms that is derived from the original version developed by Bond and colleagues [35]. Participants rate each item on a nine-point Likert scale ranging from 1 (strongly disagree) to 9 (strongly agree). This instrument investigates 20 defense mechanisms (sublimation, humor, anticipation, suppression, withdrawal, pseudo-altruism, idealization, reaction formation, projection, passive aggressive behavior, acting-out, isolation, devaluation, autistic fantasy, denial, displacement, dissociation, splitting, rationalization and somatization) [36]. Defenses are categorized into three ordered domains which represent defense styles: mature (eight items e.g., "I'm able to keep a problem out of my mind until I have time to deal with it"), neurotic (eight items e.g., "If I have an aggressive thought, I feel the need to do something to compensate for it"), and immature (24 items e.g., "If my boss bugged me, I might make a mistake in my work or work more slowly so as to get back at him"). The findings of the factor structure of the DSQ-40 are inconsistent, showing three-, four-, and five-factor solutions; for this reason, in the present study we did not use a categorization of defenses [37-41]. The DSQ-40 has been validated in many countries, including Italy [37]. 


\subsection{Data Analysis}

Descriptive statistics were used to characterize the sample in terms of sociodemographic and clinical variables. The chi-squared test $\left(\chi^{2}\right)$ and analysis of variance (ANOVA) were used to evaluate differences between patients and caregivers, and gender. The homogeneity of variance was verified with the Levene test. The Brown-Forsythe and Welch tests were used when the homogeneity of variance assumption did not hold for the data. The mean ages were compared with the Student's $t$-test for independent samples.

The risk of depressive and PTSD symptoms in relation to coping strategies and defense mechanisms was separately estimated in patients and caregivers. Logistic regression models were used to explore significant factors associated with the two outcomes: depression (BDI) and PTSD symptoms (DTS). This was achieved by treating the effective response as the dependent variable and other factors as independent variables, which were introduced into the model as dichotomous ordinal variables and scored according to each respective cut-off, or to the mean for the five-factor "coping" structure. According to the original cut-offs proposed by Beck et al. [25], "13" was chosen as the end point for the BDI-II (absence or presence of depressive symptoms), while " 40 " was selected for the DTS (absence or presence of post-traumatic symptoms) [28,42]. Full and stepwise models were used to identify the combination of independent variables giving the best explanation of the outcome (using the overall predictive accuracy and $\mathrm{R}^{2}$ statistic). As measures of association, odds ratios (OR) and their $95 \%$ confidence intervals $(\mathrm{CI})$ were reported. ORs greater than 1 indicated higher risks for depression and post-traumatic stress of being patient/caregiver or male/female or a strategy of coping and defense mechanisms activated, according to the model. The results were considered significant at a $p$-value less than 0.05. All analyses were performed using SPSS v25.0 for Windows (IBM, Armonk, NY, USA).

\section{Results}

The sample (Table 1) comprised 108 patients (67\% men) and 94 caregivers ( $72 \%$ women) with an average age of $66.9(\mathrm{SD}=7.4)$ and 56.3 years $(\mathrm{SD}=14.1)$, respectively. There were significant differences for gender $\left(\chi^{2}=30.6 ; p<0.001\right)$ and age $(t=-6.5 ; p<0.001)$ between patients and caregivers. Approximately $46 \%$ of patients had a lower secondary diploma, while $48 \%$ of caregivers had an upper secondary diploma $\left(\chi^{2}=16.3 ; p<0.001\right)$. Most patients were retired or housewives $(36 \%)$ or blue collar workers (engaged in manual labor) $(35 \%)$, whereas $33 \%$ of caregivers were employees (workers engaged in non-manual labor) $\left(\chi^{2}=17.2 ; p<0.001\right)$. Most subjects in the total population were married, with no previous experience of psychological counseling and no psychiatric drug use (e.g., antidepressants, antipsychotics, anxiolytics, etc.). Individual psychotherapy had not been recommended to the majority of participants, whereas group psychotherapy had been recommended to about half. Among the patients, $61 \%$ of men had occupational exposure and $56 \%$ of women had environmental exposure to asbestos. There were also gender significant differences in average age $(\mathrm{t}=3.5 ; p=0.001)$, educational level $\left(\chi^{2}=7.9 ; p=0.048\right)$ and job $\left(\chi^{2}=13.5 ; p=0.004\right)$. The average age was 65.0 years $(\mathrm{SD}=11.2)$ for men and 59.2 years for women $(\mathrm{SD}=12.5)$. Most men $(46 \%)$ had a lower secondary diploma, while $42 \%$ of women had an upper secondary diploma. Moreover, $38 \%$ of men were blue collar workers (38\%), whereas $38 \%$ of the women were retired or housewives (Table 2).

The results of ANOVA analysis (Table 3) showed that MM patients and caregivers differ significantly only in DSQ Suppression and DTS scores. Specifically, MM patients reported a higher level of suppression $(\mathrm{M}=5.1 ; \mathrm{SD}=2.2)$ compared to caregivers $(\mathrm{F}=6.8 ; p=0.010)$. However, the latter were more severely traumatized $(\mathrm{F}=14.3 ; p<0.001)$. 
Table 1. Sociodemographic characteristics of patients $(\mathrm{N}=108)$ and caregivers $(\mathrm{N}=94)$.

\begin{tabular}{|c|c|c|c|c|c|c|}
\hline & \multirow{2}{*}{ Variables } & \multicolumn{2}{|c|}{ Patients } & \multicolumn{2}{|c|}{ Caregivers } & \multirow{2}{*}{$t$-Test; $p$-Value } \\
\hline & & $\mathbf{N}$ & $\%$ & $\mathbf{N}$ & $\%$ & \\
\hline \multicolumn{7}{|l|}{ Gender } \\
\hline & Men & 72 & 66.7 & 26 & 27.7 & \multirow{2}{*}{$\chi^{2}=30.62 ; p<0.001$} \\
\hline & Women & 36 & 33.3 & 68 & 72.3 & \\
\hline Age (mean \pm SD) & & \multicolumn{2}{|c|}{$66.9 \pm 7.4$} & \multicolumn{2}{|c|}{$56.3 \pm 14.1$} & $t$-test $=-6.54 ; p<0.001$ \\
\hline \multicolumn{7}{|l|}{ Educational level } \\
\hline & Primary school & 18 & 16.7 & 9 & 9.6 & \multirow{4}{*}{$\chi^{2}=16.29 ; p<0.001$} \\
\hline & Lower secondary school & 50 & 46.3 & 28 & 29.8 & \\
\hline & Upper secondary school & 23 & 21.3 & 45 & 47.9 & \\
\hline & Univerity degree & 17 & 15.7 & 12 & 12.8 & \\
\hline \multicolumn{7}{|l|}{ Job } \\
\hline & Blue collar workers & 38 & 35.2 & 15 & 16.0 & \multirow{4}{*}{$\chi^{2}=17.23 ; p<0.001$} \\
\hline & Employees & 23 & 21.3 & 31 & 33.0 & \\
\hline & Entrepreneurs/Self-employed & 8 & 7.4 & 20 & 21.3 & \\
\hline & Retired/Housewife & 39 & 36.1 & 28 & 29.8 & \\
\hline \multicolumn{7}{|l|}{ Marital status } \\
\hline & Married & 83 & 76.9 & 76 & 80.9 & \multirow{2}{*}{$\chi^{2}=0.48 ; p=0.489$} \\
\hline & Single* & 25 & 23.1 & 18 & 19.1 & \\
\hline \multicolumn{7}{|l|}{ Psychotherapy } \\
\hline & Individual & 9 & 8.4 & 3 & 3.3 & $\chi^{2}=2.32 ; p=0.13$ \\
\hline & Group & 46 & 43.0 & 42 & 46.2 & $\chi^{2}=0.20 ; p=0.66$ \\
\hline \multirow{2}{*}{\multicolumn{7}{|c|}{$\begin{array}{c}\text { Previous } \\
\text { psychological } \\
\text { counseling }\end{array}$}} \\
\hline & & & & & & \\
\hline & Yes & 14 & 13.0 & 11 & $\begin{array}{l}0.3 \\
11.7\end{array}$ & $\chi^{2}=0.07 ; p=0.79$ \\
\hline \multicolumn{7}{|l|}{ Psychiatric drug use } \\
\hline & No & 86 & 79.6 & 79 & 84.0 & \multirow{2}{*}{$\chi^{2}=0.65 ; p=0.42$} \\
\hline & Yes & 22 & 20.4 & 15 & 16.0 & \\
\hline
\end{tabular}

* Single + widower + separated.

Table 2. Sociodemographic characteristics of men $(\mathrm{N}=98)$ and women $(\mathrm{N}=104)$.

\begin{tabular}{|c|c|c|c|c|c|}
\hline \multirow{2}{*}{ Variables } & \multicolumn{2}{|c|}{ Men } & \multicolumn{2}{|c|}{ Women } & \multirow{2}{*}{$t$-Test; $p$-Value } \\
\hline & $\mathbf{M}$ & SD & $\mathbf{M}$ & SD & \\
\hline Age (mean \pm SD) & 65.0 & 11.2 & 59.2 & 12.5 & $t$-test $=3.49 ; p=0.001$ \\
\hline \multicolumn{6}{|l|}{ Educational level } \\
\hline Primary school & 13 & 13.3 & 14 & 13.5 & \multirow{4}{*}{$\chi^{2}=7.91 ; p=0.048$} \\
\hline Lower secondary school & 45 & 45.9 & 33 & 31.7 & \\
\hline Upper secondary school & 24 & 24.5 & 44 & 42.3 & \\
\hline Univerity degree & 16 & 16.3 & 13 & 12.5 & \\
\hline \multicolumn{6}{|l|}{ Job } \\
\hline Blue collar workers & 37 & 37.8 & 16 & 15.4 & \multirow{4}{*}{$\chi^{2}=13.49 ; p=0.004$} \\
\hline Employees & 21 & 21.4 & 33 & 31.7 & \\
\hline Entrepreneurs/Self-employed & 13 & 13.3 & 15 & 14.4 & \\
\hline Retired/Housewife & 27 & 27.6 & 40 & 38.5 & \\
\hline \multicolumn{6}{|l|}{ Marital status } \\
\hline Married & 81 & 82.7 & 78 & 75.0 & \multirow{2}{*}{$\chi^{2}=1.76 ; p=0.184$} \\
\hline Single ** & 17 & 17.3 & 26 & 25.0 & \\
\hline
\end{tabular}


Table 2. Cont.

\begin{tabular}{ccccccc}
\hline \multirow{2}{*}{ Variables } & \multicolumn{2}{c}{ Men } & \multicolumn{2}{c}{ Women } & \multirow{2}{*}{$t$-Test; $p$-Value } \\
\cline { 2 - 5 } & $\mathbf{M}$ & SD & $\mathbf{M}$ & SD & \\
\hline Psychotherapy & & & & & \\
\hline Individual & 7 & 7.2 & 5 & 4.9 & $\chi^{2}=0.47 ; p=0.49$ \\
Group & 42 & 43.3 & 46 & 45.5 & $\chi^{2}=0.10 ; p=0.75$ \\
\hline Previous psychological counseling & & & & & \\
\hline No & 89 & 90.8 & 88 & 84.6 & \multirow{2}{*}{$\chi^{2}=1.79 ; p=0.18$} \\
Yes & 9 & 9.2 & 16 & 15.4 & \\
\hline Psychiatric drug use & & & & & \\
\hline No & 82 & 83.7 & 83 & 79.8 & \multirow{2}{*}{$\chi^{2}=0.50 ; p=0.48$} \\
\hline Yes & 16 & 16.3 & 21 & 20.2 & \\
\hline Eccuposure * & & & & & \\
Environmental & 42 & 60.9 & 15 & 44.1 & \multirow{2}{*}{$\chi^{2}=2.59 ; p=0.11$} \\
\hline
\end{tabular}

* Only patients; ${ }^{* *}$ single + widower + separated.

Table 3. ANOVA analysis results of patients $(\mathrm{N}=108)$ and caregivers $(\mathrm{N}=94)$.

\begin{tabular}{|c|c|c|c|c|c|}
\hline \multirow{2}{*}{ Variables } & \multicolumn{2}{|c|}{ Patients } & \multicolumn{2}{|c|}{ Caregivers } & \multirow{2}{*}{ F; $p$-Value } \\
\hline & Mean & SD & Mean & SD & \\
\hline $\begin{array}{c}\text { COPE * } \\
\text { Social support }\end{array}$ & 16.5 & 14.2 & 17.7 & 15.3 & $0.33 ; p=0.564$ \\
\hline Avoidance strategies & 15.4 & 13.5 & 14.3 & 12.3 & $0.33 ; p=0.564$ \\
\hline Positive attitude & 19.7 & 16.2 & 18.1 & 14.8 & $0.54 ; p=0.462$ \\
\hline Problem solving & 17.7 & 15.0 & 18.6 & 15.6 & $0.16 ; p=0.686$ \\
\hline Turning to religion & 13.7 & 11.0 & 14.5 & 11.5 & $0.24 ; p=0.625$ \\
\hline $\begin{array}{c}\text { DSQ } \\
\text { Sublimation }\end{array}$ & 5.0 & 2.5 & 5.2 & 2.2 & $0.35 ; p=0.553$ \\
\hline Humor & 5.2 & 2.6 & 5.4 & 2.2 & $0.36 ; p=0.548$ \\
\hline Anticipation & 5.2 & 2.3 & 5.3 & 1.7 & $0.12 ; p=0.733$ \\
\hline Suppression & 5.1 & 2.2 & 4.3 & 1.9 & $6.82 ; p=0.010$ \\
\hline Withdrawal & 4.7 & 2.3 & 4.9 & 2.0 & $0.48 ; p=0.489$ \\
\hline Pseudo-altruism & 4.7 & 4.4 & 4.5 & 1.8 & $0.08 ; p=0.779$ \\
\hline Idealization & 4.4 & 2.3 & 4.5 & 2.3 & $0.04 ; p=0.835$ \\
\hline Reaction formation & 4.6 & 2.1 & 4.9 & 2.0 & $0.68 ; p=0.411$ \\
\hline Projection & 3.0 & 2.1 & 3.2 & 2.0 & $0.91 ; p=0.343$ \\
\hline Passive aggressive behavior & 3.2 & 2.0 & 3.2 & 1.9 & $0.02 ; p=0.891$ \\
\hline Acting out & 4.3 & 2.0 & 4.3 & 2.2 & $0.01 ; p=0.948$ \\
\hline Isolation & 3.9 & 2.2 & 3.6 & 2.0 & $0.71 ; p=0.402$ \\
\hline Devaluation & 4.5 & 2.1 & 4.3 & 2.0 & $0.38 ; p=0.538$ \\
\hline Autistic fantasy & 3.5 & 2.6 & 3.1 & 2.3 & $1.36 ; p=0.245$ \\
\hline Denial & 3.3 & 2.2 & 2.7 & 1.9 & $3.32 ; p=0.070$ \\
\hline Displacement & 2.8 & 1.9 & 3.1 & 1.9 & $1.01 ; p=0.317$ \\
\hline Dissociation & 3.7 & 2.4 & 3.3 & 2.0 & $1.95 ; p=0.164$ \\
\hline Splitting & 4.1 & 2.0 & 3.9 & 2.2 & $0.40 ; p=0.529$ \\
\hline Rationalization & 5.6 & 2.3 & 5.1 & 1.8 & $3.56 ; p=0.061$ \\
\hline Somatization & 2.8 & 2.4 & 2.9 & 1.9 & $0.07 ; p=0.799$ \\
\hline BDI-II $* * *$ & 9.7 & 8.9 & 11.4 & 0.9 & $1.99 ; p=0.160$ \\
\hline DTS **** Total Score & 20.6 & 20.1 & 31.8 & 21.2 & $14.26 ; p<0.001$ \\
\hline Intrusion & 6.0 & 7.7 & 10.1 & 8.1 & $13.15 ; p<0.001$ \\
\hline Avoidance/Numbing & 6.5 & 7.6 & 7.7 & 6.0 & $1.39 ; p=0.239$ \\
\hline Hyperarousal & 8.7 & 9.3 & 14.1 & 11.1 & $13.42 ; p<0.001$ \\
\hline
\end{tabular}

* Coping Orientation to Problems Experienced - New Italian Version; ${ }^{* *}$ Defense Style Questionnaire; ${ }^{* * *}$ Beck Depression Inventory, Second Edition; ${ }^{* * * *}$ Davidson Trauma Scale. 
Various statistically significant differences were observed between men and women in terms of behavior as well as coping strategies and defense mechanisms (Table 4 ). Women were more depressed $(\mathrm{F}=13.5 ; p<0.001)$ and traumatized $(\mathrm{F}=25.2 ; p<0.001)$ than men and used more coping strategies, particularly social support $(\mathrm{F}=10.7 ; p<0.001)$, avoidance $(\mathrm{F}=3.9 ; p=0.049)$, positive attitude $(\mathrm{F}=4.6$; $p=0.033)$, problem solving $(\mathrm{F}=4.6 ; p=0.032)$ and turning to religion $(\mathrm{F}=6.0 ; p=0.015)$. For defense mechanisms, women achieved higher scores than men for sublimation $(\mathrm{F}=10.7 ; p<0.00)$, anticipation $(\mathrm{F}=4.9 ; p=0.027)$, withdrawal $(\mathrm{F}=26.6 ; p<0.001)$, reaction formation $(\mathrm{F}=7.0 ; p=0.009)$, passive aggressive behavior $(\mathrm{F}=9.8 ; p=0.002)$, acting out $(\mathrm{F}=5.7 ; p=0.018)$, displacement $(\mathrm{F}=8.1 ; p=0.005)$ and somatization $(\mathrm{F}=10.1 ; p=0.002)$. On the other hand, men reported a higher level of dissociation than women $(\mathrm{F}=4.8 ; p=0.029)$.

Table 4. ANOVA analysis results of men $(\mathrm{N}=98)$ and women $(\mathrm{N}=104)$.

\begin{tabular}{|c|c|c|c|c|c|}
\hline \multirow{2}{*}{ Variables } & \multicolumn{2}{|c|}{ Men } & \multicolumn{2}{|c|}{ Women } & \multirow{2}{*}{ F; $p$-Value } \\
\hline & Mean & SD & Mean & SD & \\
\hline $\begin{array}{c}\text { COPE * } \\
\text { Social support }\end{array}$ & 13.7 & 12.8 & 20.3 & 15.7 & $10.70 ; p<0.001$ \\
\hline Avoidance strategies & 13.0 & 12.2 & 16.6 & 13.5 & $3.92 ; p=0.049$ \\
\hline Positive attitude & 16.6 & 14.9 & 21.2 & 15.9 & $4.59 ; p=0.033$ \\
\hline Problem solving & 15.7 & 14.7 & 20.3 & 15.4 & $4.64 ; p=0.032$ \\
\hline $\begin{array}{c}\text { Turning to religion } \\
\text { DSQ }\end{array}$ & 12.1 & 10.4 & 15.9 & 11.8 & $5.97 ; p=0.015$ \\
\hline Sublimation & 4.5 & 2.3 & 5.6 & 2.3 & $10.70 ; p<0.001$ \\
\hline Humor & 5.4 & 2.5 & 5.3 & 2.4 & $0.77 ; p=0.781$ \\
\hline Anticipation & 5.0 & 2.1 & 5.6 & 2.0 & $4.94 ; p=0.027$ \\
\hline Suppression & 4.7 & 2.1 & 4.7 & 2.2 & $0.00 ; p=0.987$ \\
\hline Withdrawal & 4.0 & 1.9 & 5.5 & 2.2 & $26.60 ; p<0.001$ \\
\hline Pseudo-altruism & 4.3 & 4.5 & 4.9 & 1.9 & $1.34 ; p=0.248$ \\
\hline Idealization & 4.1 & 2.3 & 4.7 & 2.3 & $3.26 ; p=0.072$ \\
\hline Reaction formation & 4.3 & 2.0 & 5.1 & 2.0 & $6.99 ; p=0.009$ \\
\hline Projection & 2.9 & 1.9 & 3.2 & 2.2 & $0.91 ; p=0.342$ \\
\hline Passive aggressive behavior & 2.8 & 1.8 & 3.6 & 2.0 & $9.77 ; p=0.002$ \\
\hline Acting out & 3.9 & 1.9 & 4.6 & 2.2 & $5.66 ; p=0.018$ \\
\hline Isolation & 4.0 & 2.0 & 3.6 & 2.2 & $1.56 ; p=0.214$ \\
\hline Devaluation & 4.5 & 2.1 & 4.3 & 2.0 & $0.71 ; p=0.402$ \\
\hline Autistic fantasy & 3.5 & 2.4 & 3.3 & 2.6 & $0.30 ; p=0.584$ \\
\hline Denial & 3.2 & 2.1 & 2.8 & 2.1 & $1.62 ; p=0.204$ \\
\hline Displacement & 2.5 & 1.7 & 3.3 & 2.1 & $8.09 ; p=0.005$ \\
\hline Dissociation & 3.9 & 2.3 & 3.2 & 2.1 & $4.83 ; p=0.029$ \\
\hline Splitting & 3.9 & 1.9 & 4.1 & 2.3 & $0.58 ; p=0.447$ \\
\hline Rationalization & 5.4 & 1.9 & 5.4 & 2.2 & $0.00 ; p=0.996$ \\
\hline Somatization & 2.4 & 1.8 & 3.3 & 2.4 & $10.07 ; p=0.002$ \\
\hline BDI-II *** & 8.2 & 8.5 & 12.7 & 8.7 & $13.49 ; p<0.001$ \\
\hline DTS **** Total Score & 18.5 & 18.8 & 33.0 & 21.9 & $25.19 ; p<0.001$ \\
\hline Intrusion & 4.7 & 5.9 & 11.0 & 8.8 & $35.37 ; p<0.001$ \\
\hline Avoidance/Numbing & 5.5 & 6.4 & 8.5 & 7.1 & $10.08 ; p=0.002$ \\
\hline Hyperarousal & 8.3 & 9.2 & 13.9 & 11.0 & $15.41 ; p<0.001$ \\
\hline
\end{tabular}

\footnotetext{
* Coping Orientation to Problems Experienced - New Italian Version; ${ }^{* *}$ Defense Style Questionnaire; ${ }^{* * *}$ Beck
} Depression Inventory, Second Edition; ${ }^{* * * *}$ Davidson Trauma Scale.

There were 25 patients and 31 caregivers above the cutoff point for depression (BDI-II), and 12 patients and 30 caregivers above that for post-traumatic symptoms (DTS). The intergroup difference was significant only for post-traumatic symptoms $(p=0.042)$. Independent variables associated with BDI-II and DTS were examined by logistic regression analysis separately for patients and caregivers. 
In patients, a high risk of depression was associated with high use of DSQ Isolation (OR: 53.33; 95\% CI: 3.22-882.30; $p=0.01$ ) and DSQ Somatization (OR: 16.97; 95\% CI: 1.04-275.90; $p=0.05$ ). Conversely, high use of Coping-Turning to religion (OR: $0.003 ; 95 \%$ CI: $0.000-0.214 ; p=0.01$ ) and DSQ Humor (OR: $0.002 ; 95 \%$ CI: $0.000-0.286 ; p=0.01$ ) was found to have a protective effect against depression (accuracy of model: $88 \%, \mathrm{R}^{2}=0.684$ ). In terms of effect estimates on post-traumatic symptoms, statistically significant risks were observed for DSQ Passive-aggressive behavior (OR: 24.88; 95\% CI: 1.67-369.92; $p=0.02$ ) and Coping-Avoidance strategies (OR: 165.87; 95\% CI: 3.37-8173.81; $p=0.01$ ), while DSQ Autistic fantasy (OR: $0.007 ; 95 \%$ CI: $0.000-0.414 ; p=0.02$ ) and Coping-Positive attitude (OR: $0.0001 ; 95 \%$ CI: $0.000-0.399 ; p=0.03$ ) had a potentially protective effect (accuracy of model: $\left.92.6 \% ; R^{2}=0.660\right)$.

Among caregivers, women had an elevated risk of depression (OR: 6.39, 95\% CI: 1.16-35.38; $p=0.03$ ), especially those with a high use of Coping-Avoidance (OR: 8.93; 95\% CI: 2.08-38.36; $p=0.003$ ), DSQ Acting out (OR: 5.81; 95\% CI: 1.34-25.08; $p=0.02$ ), DSQ Devaluation (OR: 11.71; 95\% CI: 2.27-60.45; $p=0.003$ ), and DSQ Displacement (OR: 9.98; 95\% CI: 2.17-46.00; $p=0.003$ ). Meanwhile, a protective effect was observed in caregivers aged $61-69$ years (OR: $0.10 ; 95 \%$ CI: $0.01-0.84 ; p=0.03$ ) and those with a high use DSQ Sublimation (OR: $0.08 ; 95 \%$ CI: 0.02-0.40; $p=0.002$ ) (accuracy of model: $83 \%$; $\mathrm{R}^{2}=0.570$ ). With regard to effect estimates on post-traumatic symptoms, a statistically significant risk was observed for DSQ Acting out (OR: 7.00; 95\% CI: 1.10-44.47; $p=0.04$ ) (accuracy of model: $81.9 \%$; $\left.\mathrm{R}^{2}=0.565\right)$.

\section{Discussion}

The present study investigated the adaptive conscious/unconscious processes used to manage the emotional distress related to MM diagnosis in an Italian NPCS group of patients and familial caregivers. The sample adequately represented the incidence of the disease [1,4]. The results showed that patients and caregivers did not differ significantly with respect to the use of adaptational strategies, except for suppression. Emotional suppression is often used by cancer patients to not think about and verbalize the negative emotions related to cancer; nevertheless, there is evidence that this strategy seems to increase their levels of psychological distress [43-46]. This attempt to suppress unpleasant feelings and the idea of death has also been previously found in MM patients [13]. Thus, it could be possible that MM patients consciously decide to suppress thinking about the situation they are going through in order to regulate painful emotions they are not prepared to express.

Caregivers were more severely traumatized than MM patients, reporting a higher incidence of intrusive thoughts about death and physiologic hyperactivation. A possible cause is feelings of guilt, which is a key emotion in the experience of cancer caregivers that can compromise their psychosocial and somatic adjustment to cancer [47]. Caregivers in NPCSs are themselves exposed to asbestos and are thus at potential risk of developing and dying from MM. Hence, they may experience a form of survivor's guilt for remaining healthy while their loved one(s) are expected to pass away $[5,13,14]$. Recent studies have consistently linked the emotion of guilt to post-traumatic symptomatology [48-51], suggesting a causal role for trauma-related guilt in this phenomenon [52,53].

Interestingly, gender appears to play a pivotal role in the understanding of both the emotional impact of the diagnosis of MM and activation of protective responses. Women showed higher levels of depressive and post-traumatic symptoms, as well as a more frequent use of many kinds of coping strategies and defense mechanisms, to face these negative experiences. Moreover, women caregivers were at greater risk than men of developing depressive symptomology, which is in accordance with the results of longitudinal studies demonstrating a higher risk of depressive disorders in women as compared to men $[54,55]$.

Logistic regression analyses showed that adaptive processes were unconsciously activated in response to internal and external threats in both patients and caregivers at NPCSs. In fact, a few coping strategies partially explained the risk of developing depressive feelings, with avoidance strategies being a risk factor for caregivers and turning to religion serving as a protective factor in patients. 
Meanwhile, in patients, conscious strategies partially explained successive post-traumatic symptoms, with avoidance strategies and positive attitude as risk and protective factors, respectively.

Avoidance-oriented coping (i.e., avoidance, denial and withdrawal) is defined as the cognitive and behavioral attempts to distance oneself both from a problem and the related emotions $[33,56]$. These findings support the notion that avoidance strategies are the most frequent used to cope with MM-related emotional distress $[9,10,14,15,57]$. Nonetheless, the pervasive activation of avoidance strategies plays a pivotal role in the maintenance of post-traumatic symptoms [58-60] and increase their severity over time [61-64].

The protective effects of religious devotion may be attributable to its role as filter for aggression and anger [65]. Relying on religion allows patients to place their past, present, and future in a transcendent dimension $[66,67]$, which may increase their hope and the feeling that they can manage their difficulties $[68,69]$, provide comfort as they undergo chemotherapy and face its consequences as well as death, and explain their current situation [70,71]. From a psychoanalytic point of view, this can help people place their subjectivity at the center of their experiences, allowing them to tolerate the adversity that they face and prepare for death instead of seeking a target to blame. A positive attitude could be conceptualized as an adaptive coping strategy characterized by acceptation, the containment of painful emotions and a reinterpretation of a stressful event in a more positive way [32]. Our findings suggest that people who are able to positively change the value of thoughts related to the disease are less vulnerable to incur in post-traumatic conditions. It is possible that the efforts to assimilate-and not to avoid-intrusive negative thoughts and the traumatic emotions related to MM led to a more positive cognitive process of the cancer experience. Thus, maintaining optimism and positive expectations toward MM and treatments and believing that a stressful present can ameliorate in the future may restore a sense of self-efficacy and agency [10], promoting resilience and protecting from post-traumatic conditions [72].

Data suggest that defense mechanisms are important both for prevention and development of successive depressive or post-traumatic conditions. Psychoanalytic theories conceptualize defenses as a continuum, differing in degree of maturity, where primitive and/or immature mechanisms imply a severe alteration of reality testing, while more mature defenses allow for management of threatening feelings without distorting reality [73]. Our data support previous results showing that a pervasive use of immature defenses is a risk factor for the development of different forms of psychopathology [74-77]. For example, the use of immature defense mechanisms, such as somatization for patients, and acting out and devaluation for caregivers, increase the risk of incurring in depressive conditions, while the use of more mature defenses as humor for the patients and as sublimation for the caregivers, protect the Ego from depressive feelings. Sublimation could be conceptualized as a mature and adaptive mechanism allowing the subject to transform anxieties, aggressiveness, and inner conflicts, and thus restoring an inner balance [73]. It should be noted that similar results were also reported in previous research that took place in the same NPCS, identified as a resilient community able to transform unwanted feelings of rage, fear of death and desire of revenge into socially well-accepted claim actions for justice [13,76].

In line with this notion, we observed that immature defenses (i.e., passive-aggressive behavior in patients and acting out in caregivers) significantly increased the risk of developing post-traumatic conditions, although, surprisingly, autistic fantasy had a protective effect in patients. Autistic fantasy allows individuals to withdraw into a different state of consciousness so that they can temporarily distance themselves from external/internal stressful stimuli and their overwhelming impact [73]. In the short term, this defensive strategy can protect patients from the negative effects of a reality that is unmanageable on both psychological and behavioral levels; however, over time it can increase the risk of developing post-traumatic symptoms stemming from the inability to find meaning in the traumatic experience. Moreover, not only can avoidant defense mechanisms worsen post-traumatic conditions, the latter can promote the use of avoidance-coping strategies [78] on both emotional and behavioral levels. Indeed, people who are most severely traumatized by the psychological impact of 
MM frequently withdraw emotionally and socially [13], giving rise to a vicious cycle that can enhance their feelings of social isolation $[18,79,80]$.

\section{Conclusions}

The findings of this study add to previous knowledge on psychological distress following an MM diagnosis by demonstrating that unconscious adaptive processes play a major role in the way patients and caregivers respond to overwhelming feelings related to the disease. Such evidence strongly suggests the need for psychological interventions addressed to both patients and caregivers, and that take into account not merely coping strategies, but also unconscious somatopsychic processes. In particular, from our clinical point of view, we believe that group interventions addressed to patients and caregivers together could constitute the better setting for the elaboration of unconscious processes connected to death anxieties aroused from MM, considering that the diagnosis has a traumatic impact on all the family members and on the relationship between them. Such interventions would be better time-limited, given the short life-expectancy for MM. Moreover, we suggest a somatopsychic focus for those interventions. Indeed, as suggested by our results, often both patients and caregivers rely on unconscious defense mechanisms to protect themselves from overwhelming emotions connected to the diagnosis, thus lacking a full and conscious comprehension of practical and affective consequences of the disease. Thus, a psychotherapeutic work with a somatopsychic focus can help restore the connection between the impact of physical symptoms and emotions, feelings, and fantasies related to the disease [77].

There were some limitations to our study. Firstly, we used only self-report measures that may have been influenced by social desirability biases. Secondly, since we did not collect any clinical data, we were unable to analyze our results based on disease stage or localization. Thirdly, since we considered MM patients and caregivers of the NPCS as specific subgroups, no generalization can be made regarding the whole MM population. Nevertheless, our study had a large sample size and used a variety of tests along with appropriate statistical models to identify relevant risk factors for, and protective factors against, psychological distress after a diagnosis of MM. Further research is needed to determine whether our findings are applicable to populations at other NPCSs.

Author Contributions: F.G. design the study and managed the research process. G.S. and F.G. collect data. M.B. and A.B. performed statistical analyses. F.G., A.G., C.M., I.G.F., A.M. and G.S. performed the literature review. M.B., A.G. and F.G. took primary responsibility for initial drafting and were responsible for subsequent collation of inputs and redrafting. All authors critically revised the manuscript and approved its final version. All authors have read and agreed to the published version of the manuscript.

Funding: This work was partially founded by INAIL, Research Plan 2016-2018, Project P9O3, BRIC n. 59.

Conflicts of Interest: The authors declare that the research was conducted in the absence of any commercial or financial relationships that could be construed as a potential conflict of interest.

Data Availability Statement: The dataset is available on request to the corresponding author.

Ethics Statement: The study involving was approved by the Internal Review Board for Psychological Research of University of Turin and Ethical Committee of the Azienda Ospedaliera SS Antonio e Biagio e Cesare Arrigo (AVPM-14/11/2014). Written informed consent to participate in this study was provided by MM patients and caregivers.

\section{References}

1. Furuya, S.; Chimed-Ochir, O.; Takahashi, K.; David, A.; Takala, J. Global asbestos disaster. Int. J. Environ. Res. Public Health 2018, 15, 1000. [CrossRef]

2. Marinaccio, A.; Binazzi, A.; Di Marzio, D.; Scarselli, A.; Verardo, M.; Mirabelli, D.; Gennaro, V.; Mensi, C.; Riboldi, L.; Merler, E.; et al. Pleural malignant mesothelioma epidemic. Incidence, modalities of asbestos exposure and occupations involved from the Italian national register. Int. J. Cancer 2012, 130, 2146-2154. [CrossRef] [PubMed] 
3. Marinaccio, A.; Binazzi, A.; Bonafede, M.; Di Marzio, D.; Scarselli, A.; Regional Operating Centres. Epidemiology of malignant mesothelioma in Italy: Surveillance systems, territorial clusters and occupations involved. J. Thorac. Dis. 2018, 10, S221-S227. [CrossRef] [PubMed]

4. Magnani, C.; Dalmasso, P.; Biggeri, A.; Ivaldi, C.; Mirabelli, D.; Terracini, B. Increased risk of malignant mesothelioma of the pleura after residential or domestic exposure to asbestos: A case-control study in Casale Monferrato, Italy. Environ. Health Perspect. 2001, 109, 915-919. [CrossRef] [PubMed]

5. Binazzi, A.; Marinaccio, A.; Corfiati, M.; Bruno, C.; Fazzo, L.; Pasetto, R.; Pirastu, R.; Biggeri, A.; Catelan, D.; Comba, P.; et al. Mesothelioma incidence and asbestos exposure in Italian national priority contaminated sites. Scand. J. Work Environ. Health 2017, 43, 550-559. [CrossRef]

6. Guglielmucci, F.; Franzoi, I.G.; Barbasio, C.P.; Borgogno, F.V.; Granieri, A. Helping traumatized people survive: A psychoanalytic intervention in a contaminated Site. Front. Psychol. 2014, 5, 1419. [CrossRef]

7. Borgogno, F.V.; Franzoi, I.G.; Barbasio, C.P.; Guglielmucci, F.; Granieri, A. Massive trauma in a community exposed to asbestos: Thinking and dissociation in the population of Casale Monferrato. Br. J. Psychother. 2015, 31, 419-432. [CrossRef]

8. Girgis, S.; Smith, A.B.; Lambert, S.; Waller, A.; Girgis, A. "It sort of hit me like a baseball bat between the eyes": A qualitative study of the psychosocial experiences of mesothelioma patients and carers. Support. Care Cancer 2019, 27, 631-638. [CrossRef]

9. Bonafede, M.; Ghelli, M.; Corfiati, M.; Rosa, V.; Guglielmucci, F.; Granieri, A.; Branchi, C.; Iavicoli, S.; Marinaccio, A. The psychological distress and care needs of mesothelioma patients and asbestos-exposed subjects: A systematic review of published studies. Am. J. Ind. Med. 2018, 61, 400-412. [CrossRef]

10. Clayson, H.; Seymour, J.; Noble, B. Mesothelioma from the patient's perspective. Hematol. Oncol. Clin. 2005, 19, 1175-1190. [CrossRef]

11. Granieri, A.; Tamburello, S.; Tamburello, A.; Casale, S.; Cont, C.; Guglielmucci, F.; Innamorati, M. Quality of life and personality traits in patients with malignant pleural mesothelioma and their first-degree caregivers. Neuropsychiatr. Dis. Treat. J. 2013, 9, 1193-1202. [CrossRef]

12. Guglielmucci, F.; Franzoi, I.G.; Zuffranieri, M.; Granieri, A. Living in contaminated sites: Which cost for psychic health? Mediterr. J. Soc. Sci. 2015, 6, 207-214. [CrossRef]

13. Guglielmucci, F.; Franzoi, I.G.; Bonafede, M.; Borgogno, F.V.; Grosso, F.; Granieri, A. “The less I think about it, the better I feel": A thematic analysis of the subjective experience of malignant mesothelioma patients and their caregivers. Front. Psychol. 2018, 9, 205. [CrossRef]

14. Guglielmucci, F.; Bonafede, M.; Franzoi, I.G.; Granieri, A. Research and malignant mesothelioma: Lines of action for clinical psychology. Ann. Ist. Super. Sanita. 2018, 54, 149-159. [CrossRef] [PubMed]

15. Arber, A.; Spencer, L. 'It's all bad news': The first 3 months following a diagnosis of malignant pleural mesothelioma. Psychooncology 2013, 22, 1528-1533. [CrossRef] [PubMed]

16. Ball, H.; Moore, S.; Leray, A. A systematic literature review comparing the psychological care needs of patients with mesothelioma and advanced lung cancer. Eur. J. Oncol. Nurs. 2016, 25, 62-67. [CrossRef] [PubMed]

17. Moore, S.; Darlison, L.; Tod, A. Living with mesothelioma. A literature review. Eur. J. Cancer Care 2010, 19, 458-468. [CrossRef]

18. Dooley, J.J.; Wilson, J.P.; Anderson, V.A. Stress and depression of facing death: Investigation of psychological symptoms in patients with mesothelioma. Aust. J. Psychol. 2010, 62, 160-168. [CrossRef]

19. Feldman, D.B.; Periyakoil, V.S. Posttraumatic stress disorder at the end of life. J. Palliat. Med. 2006, 9, $213-218$. [CrossRef]

20. Chapple, A.; Ziebland, S.; McPherson, A. Stigma, shame, and blame experienced by patients with lung cancer: Qualitative study. BMJ 2004, 328, 1470. [CrossRef]

21. Barak, Y.; Achiron, A.; Rotstein, Z.; Elizur, A.; Noy, S. Stress associated with asbestosis: The trauma of waiting for death. Psychooncology 1998, 7, 126-128. [CrossRef]

22. Kramer, U. Coping and defence mechanisms: what's the difference?-Second act. Psychol. Psychother. 2010, 83, 207-221. [CrossRef]

23. Lebovits, A.H.; Chahinian, A.P.; Holland, J.C. Exposure to asbestos: Psychological responses of mesothelioma patients. Am. J. Ind. Med. 1983, 4, 459-466. [CrossRef] 
24. Romano, C.; Santoro, P.E.; Marini Bettolo, P.; Zaccaria, E. Evaluation of the psychological well-being and coping strategies in a population of 34 ex asbestos exposed on its work place. G. Ital. Med. Lav. Ergon. 2007, 29, 681-683.

25. Beck, A.; Steer, R.; Brown, G. Manual for the Beck Depression Inventory-II; Psychological Corporation: San Antonio, TX, USA, 1996.

26. Wang, Y.P.; Gorenstein, C. Psychometric properties of the Beck Depression Inventory-II: A comprehensive review. Rev. Bras. Psiquiatr. 2013, 35, 416-431. [CrossRef] [PubMed]

27. Ghisi, M.; Flebus, G.B.; Montano, A.; Sanavio, E.; Sica, C. Beck Depression Inventory-II. BDI-II. Manuale; O.S. Organizzazioni Speciali: Firenze, Italy, 1996.

28. Davidson, J.R.T.; Book, S.W.; Colket, J.T.; Tupler, L.A.; Roth, S.; David, D.; Hertzberg, M.; Mellman, T.; Beckham, J.C.; Smith, R.D.; et al. Assessment of a new self-rating scale for posttraumatic stress disorder. Psychol. Med. 1997, 27, 153-160. [CrossRef]

29. Davidson, J.R.; Tharwani, H.M.; Connor, K.M. Davidson Trauma Scale (DTS): Normative scores in the general population and effect sizes in placebo-controlled SSRI trials. Depress. Anxiety 2002, 15, 75-78. [CrossRef] [PubMed]

30. Guarnerio, C.; Prunas, A.; Della Fontana, I.; Chiambretto, P. Prevalence and comorbidity of prolonged grief disorder in a sample of caregivers of patients in a vegetative state. Psychiatr. Q. 2012, 83, 65-73. [CrossRef] [PubMed]

31. Cofini, V.; Carbonelli, A.; Cecilia, M.R.; Binkin, N.; di Orio, F. Post traumatic stress disorder and coping in a sample of adult survivors of the Italian earthquake. Psychiatry Res. 2015, 229, 353-358. [CrossRef] [PubMed]

32. Sica, C.; Magni, C.; Ghisi, M.; Altoè, G.; Sighinolfi, C.; Chiri, L.R.; Franceschini, S. Coping Orientation to Problems Experienced-Nuova Versione Italiana (COPE-NVI): Uno strumento per la misura degli stili di coping [Coping Orientation to the Problems Experiences-new Italian Version (COPE-NVI)]. Psicoter. Cogn. Comport. 2008, 14, 27-53.

33. Carver, C.S.; Scheier, M.F.; Weintraub, J.K. Assessing coping strategies: A theoretically based approach. J. Pers. Soc. Psychol. 1989, 56, 267-283. [CrossRef]

34. Andrews, G.; Singh, M.; Bond, M. The defense style questionnaire. J. Nerv. Ment. Dis. 1993, 181, $246-256$. [CrossRef] [PubMed]

35. Bond, M.; Gardner, S.T.; Christian, J.; Sigal, J.J. Empirical study of self-rated defense styles. Arch. Gen. Psychiatry 1983, 40, 333-338. [CrossRef] [PubMed]

36. Vaillant, G.E.; Bond, M.; Vaillant, C.O. An empirically validated hierarchy of defense mechanisms. Arch. Gen. Psychiatry 1986, 43, 786-794. [CrossRef] [PubMed]

37. Farma, T.; Cortinovis, I. Misurare i meccanismi di difesa attraverso il "Defense Style Questionnaire" a 40 item. Attendibilità dello strumento e suo utilizzo nel contesto italiano. Ric. Psicol. 2000, 24, 127-144.

38. Rutherford, M.J.; McDermott, P.A.; Cacciola, J.S.; Alterman, A.I.; Mulvaney, F. A psychometric evaluation of the Defense Style Questionnaire in methadone patients. J. Pers. Disord. 1998, 12, 119-125. [CrossRef]

39. Spinhoven, P.; van Gaalen, H.A.E.; Abraham, R.E. The Defense Style Questionnaire: A psychometric examination. J. Pers. Disord. 1995, 9, 124-133. [CrossRef]

40. Trijsburg, R.W.; Van T' Spijker, A.R.; Van, H.L.; Hesselink, A.J.; Duivenvoorden, H.J. Measuring overall defensive functioning with the Defense Style Questionnaire: A comparison of different scoring methods. J. Nerv. Ment. Dis. 2000, 188, 432-439. [CrossRef]

41. Wastell, C.A. Defensive focus and the Defense Style Questionnaire. J. Nerv. Ment. Dis. 1999, 187, $217-223$. [CrossRef]

42. Brewin, C.R. Systematic review of screening instruments for adults at risk of PTSD. J. Trauma Stress. 2005, 18, 53-62. [CrossRef]

43. Ando, N.; Iwamitsu, Y.; Kuranami, M.; Okazaki, S.; Nakatani, Y.; Yamamoto, K.; Watanabe, M.; Miyaoka, H. Predictors of psychological distress after diagnosis in breast cancer patients and patients with benign breast problems. Psychosomatics 2011, 52, 56-64. [CrossRef]

44. Iwamitsu, Y.; Shimoda, K.; Abe, H.; Tani, T.; Okawa, M.; Buck, R. Anxiety, emotional suppression, and psychological distress before and after breast cancer diagnosis. Psychosomatics 2005, 46, 19-24. [CrossRef] [PubMed] 
45. Nakatani, Y.; Iwamitsu, Y.; Kuranami, M.; Okazaki, S.; Shikanai, H.; Yamamoto, K.; Watanabe, M.; Miyaoka, H. The relationship between emotional suppression and psychological distress in breast cancer patients after surgery. Jpn. J. Clin. Oncol. 2014, 44, 818-825. [CrossRef] [PubMed]

46. Okazaki, S.; Iwamitsu, Y.; Masaru, K.; Todoroki, K.; Suzuki, S.; Yamamoto, K.; Hagino, M.; Watanabe, M.; Miyaoka, H. The psychological responses of outpatient breast cancer patients before and during first medical consultation. Palliat. Support. Care 2009, 7, 307-314. [CrossRef] [PubMed]

47. Spillers, R.L.; Wellisch, D.K.; Kim, Y.; Matthews, B.A.; Baker, F. Family caregivers and guilt in the context of cancer care. Psychosomatics 2008, 49,511-519. [CrossRef]

48. Beck, J.G.; McNiff, J.; Clapp, J.D.; Olsen, S.A.; Avery, M.L.; Hagewood, J.H. Exploring negative emotion in women experiencing intimate partner violence: Shame, guilt, and PTSD. Behav. Ther. 2011, 42, 740-750. [CrossRef]

49. Kubany, E.S.; Watson, S.B. Guilt: Elaboration of a multidimensional model. Psychol. Rec. 2003, 53, 51-90.

50. Lee, D.A.; Scragg, P.; Turner, S. The role of shame and guilt in traumatic events: A clinical model of shame-based and guilt-based PTSD. Br. J. Med. Psychol. 2001, 74, 451-466. [CrossRef]

51. Wilson, J.P.; Drozdek, B.; Turkovic, S. Posttraumatic shame and guilt. Trauma Violence Abuse 2006, 7, $122-141$. [CrossRef]

52. Bub, K.; Lommen, M.J.J. The role of guilt in posttraumatic stress disorder. Eur. J. Psychotraumat. 2017, 8, 1407202. [CrossRef]

53. Pugh, L.R.; Taylor, P.J.; Berry, K. The role of guilt in the development of post-traumatic stress disorder: A systematic review. J. Affect. Disord. 2015, 182, 138-150. [CrossRef]

54. Culbertson, F.M. Depression and gender: An international review. Am. Psychol. 1997, 52, 25-31. [CrossRef] [PubMed]

55. Oquendo, M.A.; Turret, J.; Grunebaum, M.F.; Burke, A.K.; Poh, E.; Stevenson, E.; Mann, J.J.; Galfalvy, H. Sex differences in clinical predictors of depression: A prospective study. J. Affect. Disord. 2013, 150, 1179-1183. [CrossRef] [PubMed]

56. Roth, S.; Cohen, L.J. Approach avoidance and coping with stress. Am. Psychol. 1986, 41, 813-819. [CrossRef]

57. Lebovits, A.H.; Chahinian, A.P.; Gorzynski, J.G.; Holland, J.C. Psychological aspects of asbestos-related mesothelioma and knowledge of high risk for cancer. Cancer Detect. Prev. 1981, 4, 181-184. [PubMed]

58. Foa, E.B.; Kozak, M.J. Emotional processing of fear: Exposure to corrective information. Psychol. Bull. 1986, 99, 20-35. [CrossRef] [PubMed]

59. Keane, T.M.; Zimmering, R.T.; Caddell, J.M. A behavioral formulation of posttraumatic stress disorder in Vietnam veterans. Behav. Ther. 1985, 8, 9-12.

60. Resick, P.A.; Schnicke, M.K. Cognitive processing therapy for sexual assault victims. J. Consult. Clin. Psychol. 1992, 60, 748-756. [CrossRef]

61. Gutner, C.A.; Rizvi, S.L.; Monson, C.M.; Resick, P.A. Changes in coping strategies, relationship to the perpetrator, and posttraumatic distress in female crime victims. J. Traum. Stress 2006, 19, 813-823. [CrossRef]

62. Jacobsen, P.B.; Sadler, I.J.; Booth-Jones, M.; Soety, E.; Weitzner, M.A.; Fields, K.K. Predictors of posttraumatic stress disorder symptomatology following bone marrow transplantation for cancer. J. Consult. Clin. Psychol. 2002, 70, 235-240. [CrossRef]

63. Krause, E.D.; Kaltman, S.; Goodman, L.A.; Dutton, M.A. Avoidant coping and PTSD symptoms related to domestic violence exposure: A longitudinal study. J. Traum. Stress 2008, 21, 83-90. [CrossRef] [PubMed]

64. Pineles, S.L.; Mostoufi, S.M.; Ready, C.B.; Street, A.E.; Griffin, M.G.; Resick, P.A. Trauma reactivity, avoidant coping, and PTSD symptoms: A moderating relationship? J. Abnorm. Psychol. 2011, 120, 240-246. [CrossRef]

65. Kao, C.-H.; Su, J.C.; Crocker, J.; Chang, J.-H. The benefits of transcending self-interest: Examining the role of self-transcendence on expressive suppression and well-being. J. Happiness Stud. 2017, 18, 959-975. [CrossRef]

66. Barberis, N.; Cernaro, V.; Costa, S.; Montalto, G.; Lucisano, S.; Larcan, R.; Buemi, M. The relationship between coping, emotion regulation, and quality of life of patients on dialysis. Int. J. Psychiatry Med. 2017, 52, 111-123. [CrossRef] [PubMed]

67. Perricone, G.; Polizzi, C.; Morales, M.R.; Marino, S.; Scacco, C.F. Functioning of family system in pediatric oncology during treatment phase. Pediatr. Hematol. Oncol. 2012, 29, 652-662. [CrossRef] [PubMed]

68. Schneider, M.A.; Mannell, R.C. Beacon in the storm: An exploration of the spirituality and faith of parents whose children have cancer. Compr. Pediatr. Nurs. 2006, 29, 3-24. [CrossRef] 
69. Rajajee, S.; Ezhilarasi, S.; Indumathi, D. Psychosocial problems in families of children with cancer. Indian J. Pediatr. 2007, 74, 837-839. [CrossRef]

70. Fontana, V.; Morales, M.; Perricone, G.; Polizzi, C. Percezione del funzionamento familiare e strategie di coping in madri di bambini affetti da neoplasia in fase trattamentale. Psicol. Della Salut. 2013, 3, 101-113. [CrossRef]

71. Piccardi, L.; Marano, A.; Geraci, M.A.; Legge, E.; D'Amico, S. Differences in coping strategies of preadolescents with and without exposure to the L'Aquila (Central Italy) 2009 earthquake. Epidemiol. Prev. 2016, 40, 53-58. [CrossRef]

72. Gallagher, M.W.; Long, L.J.; Phillips, C.A. Hope, optimism, self-efficacy, and posttraumatic stress disorder: A meta-analytic review of the protective effects of positive expectancies. J. Clin. Psychol. 2019, 76, 329-355. [CrossRef]

73. Perry, J.C.; Augusto, F.; Cooper, S.H. Assessing psychodynamic conflicts: I. Reliability of the idiographic conflict formulation method. Psychiatry 1989, 52, 289-301. [CrossRef]

74. Bond, M. Empirical studies of defense style: Relationships with psychopathology and change. Har. Rev. Psychiatry 2004, 12, 263-278. [CrossRef] [PubMed]

75. Bond, M.; Perry, J.C. Long-term changes in defense styles with psychodynamic psychotherapy for depressive, anxiety, and personality disorders. Am. J. Psychiatry 2004, 161, 1665-1671. [CrossRef] [PubMed]

76. Granieri, A.; La Marca, L.; Mannino, G.; Giunta, S.; Guglielmucci, F.; Schimmenti, A. The relationship between defense patterns and DSM-5 maladaptive personality domains. Front. Psychol. 2017, 8, 1926. [CrossRef] [PubMed]

77. Granieri, A.; Guglielmucci, F.; Costanzo, A.; Caretti, V.; Schimmenti, A. Trauma-related dissociation is linked with maladaptive personality functioning. Front. Psychiatry 2018, 9, 206. [CrossRef] [PubMed]

78. Badour, C.L.; Blonigen, D.M.; Boden, M.T.; Feldner, M.T.; Bonn-Miller, M.O. A longitudinal test of the bi-directional relations between avoidance coping and PTSD severity during and after PTSD treatment. Behav. Res. Ther. 2012, 50, 610-616. [CrossRef] [PubMed]

79. Buultjens, J.; Kozlowski, D.; Tucker, J. Dusted but connected: A case study of Australian online community for people affected by asbestos-related disease. J. Econ. Soc. Policy 2015, 17, 5. Available online: https: //epubs.scu.edu.au/jesp/vol17/iss2/5 (accessed on 2 April 2020).

80. Hughes, N.; Arber, A. The lived experience of patients with pleural mesothelioma. Int. J. Palliat. Nurs. 2008, 14, 66-71. [CrossRef]

(C) 2020 by the authors. Licensee MDPI, Basel, Switzerland. This article is an open access article distributed under the terms and conditions of the Creative Commons Attribution (CC BY) license (http://creativecommons.org/licenses/by/4.0/). 